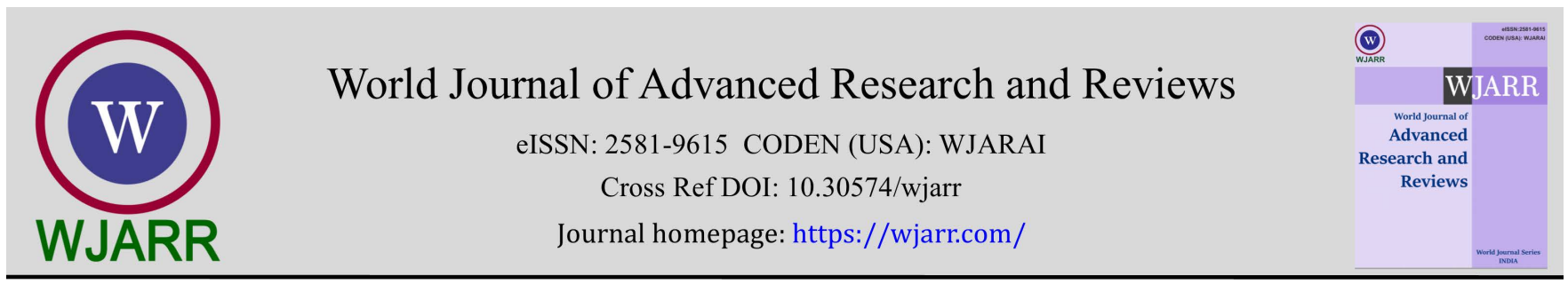

(REVIEW ARTICLE)

Check for updates

\title{
Management of occupational exposure for pregnant employee in diagnostic radiology
}

\author{
Samia Abdelgauom Fathelrahman Ahmed * \\ Department of Radiological Sciences, Collage of Applied Medical Sciences, Najran University, Najran, KSA, P.O.Box 1989 \\ KSA.
}

World Journal of Advanced Research and Reviews, 2021, 12(03), 075-082

Publication history: Received on 30 October 2021; revised on 02 December 2021; accepted on 04 December 2021

Article DOI: https://doi.org/10.30574/wjarr.2021.12.3.0663

\begin{abstract}
Occupational exposure to ionizing radiation can occur in a range of industries, medical institutions, educational and research establishments. Most radiation protection programs, regulations and guidance apply specific restrictions to the occupational exposure of pregnant workers. Both worker and the employer carry responsibility towards safety. The pregnant worker and her conceptus are best protected in a facility that uses best practices for radiation safety.

This article reviews was aimed to notify radiology managers and technologists in their management with pregnant workers. The paper describes conceptus doses for worker that are associated with radiology practice, reviews the risks and effects of in utero irradiation, and summarizes the current international and professional organizations policies, guidelines and practical aspects regarding the diagnostic radiologic examinations.
\end{abstract}

Conclusion: careful planning, and minimization of radiation dose by engaging proper radiation safety measures as needed, can allow medical staff to perform duties and normal activities without incurring significant risks to the fetus.

Keywords: Occupational exposure; Pregnancy; Conceptus; Protection; Effective dose

\section{Introduction}

Female participation in the labor force has been increasing steadily worldwide over the last few decades. As more women of reproductive age enter labor forces, their safety and health have become a priority in many nations [1].

The field of health care continues to grow, and includes a large proportion of women. Women of childbearing age must carefully consider the risks and benefits of working in this field prior to becoming pregnant and should discuss the possible reproductive hazards with their health care provider or occupational health professional [2] .

Occupational exposure to ionizing radiation can occur in a range of industries, medical institutions, educational and research establishments. Appropriate levels of radiation protection of workers are essential for the safe and justified use of radiation, radioactive material and nuclear energy [3].

The radiology department poses several unique threats to employees, including radiation exposure, repetitive stress injuries, injuries caused by wearing lead aprons or moving heavy equipment for portable studies, departments have well-defined policies for minimizing or preventing their occurrence [4], yet well-recognized safety risks, each of which can be prevented or mitigated if managed appropriately. Familiarity with these risks and their consequences, compliance with policies and guidelines on safety, and development of a culture that encourages surveillance, reporting, and early action will improving overall safety for all workers in a radiology department [5]. The management of a

\footnotetext{
${ }^{*}$ Corresponding author: Samia Abdelgaum Fathelrahman Ahmed

Department of Radiological Sciences, Collage of Applied Medical Sciences, Najran University, Najran, KSA, P.0.Box 1989 KSA.

Copyright (C) 2021 Author(s) retain the copyright of this article. This article is published under the terms of the Creative Commons Attribution Liscense 4.0.
} 
pregnant radiology worker is not straight forward, the fact that a worker is pregnant automatically involves additional protection but does not necessarily mean that she has to avoid working with ionizing radiation completely, or that she must be prevented from entering or working in radiation areas. Pregnancy in radiology involves much more than radiation protection considerations (including regulatory aspects) alone. It is complicated by individual ethical, moral and socioeconomic issues [4]. Although radiology workers are more used to radiation management than patients, It is mandatory that any decision in the assignment of working duties is funded by a careful risk assessment. Pregnant radiology staff can continue to work in areas where the radiation exposure fluctuates around background level in normal conditions and where this level can be guaranteed by strengthening the working procedures. Using existing personal dose data can support a decision [6].

The basis for the control of the occupational exposure of women who are not pregnant is the same as that for men. However, if a woman is, or may be, pregnant, additional controls have to be considered to protect the unborn child. Several factors complicate this matter. The fetus is at times more prone than the post-natal individual to deterministic injuries caused by radiation and may be more sensitive to the induction of later malignancies [7].

For most radiation workers, the small risk of exposure to low level ionizing radiation is an accepted part of the job. However, pregnant radiation workers may have heightened concerns about the risks to their unborn child $[8,9]$. These workers, have many misconceptions about the risks of ionizing radiation on the developing fetus [10]. Even minimal radiation exposure to the conceptus can worsen significant concerns on the part of the expectant mother [11] and can make worse the stresses of an already challenging work experience [12], along with the additional worry of radiation exposure to the fetus [13]. A lack of accurate knowledge of the risks associated with such exposures, or misinformation regarding these risks can cause great anxiety [14,15]. A better understanding of these risks, and ways to reduce them can help address concerns that may lead women to avoid these professions $[14,15]$.

The developing embryo is radiation sensitive throughout the prenatal period [16]. The effects of radiation exposure on the conceptus depend on multiple variables, including the gestational age, fetal cellular repair mechanisms, and absorbed radiation dose level [17]. Exposure of the conceptus to higher doses of ionizing radiation can potentially lead to two types of adverse health effects, tissue reactions and stochastic effects. Tissue reactions result from damage to multiple cells and may be severe enough to cause cell sterilization or death. Stochastic effects originate from damage to single cells that is sufficient to cause a mutation but that does not impair cell division. Stochastic effects (principally cancer) increase in likelihood as dose increases. Two factors must be addressed: the probability of an adverse outcome and the severity of such an outcome $[18,19]$

Radiation-related risks are present throughout gestation. The greatness of these risks is highly dependent on the gestational age during which exposure takes place and the conceptus' absorbed dose. Biologic systems with a high fraction of proliferating cells show high radiation responsiveness [20]. Radiation risks are most significant during preimplantation and organogenesis and the first trimester, somewhat less in the second trimester, and least in the third trimester $[15,16]$. However, there is little support in the epidemiologic literature for the hypothesis that very low doses of radiation adversely affect pregnancy outcome [5]. Most of the ways a pregnant woman who exposed to radiation, such as from a diagnostic medical exam or an occupational exposure within regulatory limits, are not likely to cause health effects for a fetus. However, accidental or intentional exposure above regulatory limits may be cause for concern. Although radiation doses to a fetus tend to be lower than the dose to the mother, due to protection from the uterus and surrounding tissues, the human embryo and fetus are sensitive to ionizing radiation at doses greater than 0.1 gray (Gy). Depending on the stage of fetal development, the health consequences of exposure at doses greater than 0.5 Gy can be severe, even if such a dose is too low to cause an immediate effect for the mother. The health consequences can include growth restriction, malformations, impaired brain function, and cancer [21]. No reliable epidemiological data are available from studies to determine which stage of pregnancy is the most sensitive for radiation-induced cancer in the offspring [5].

The risk of health effects as discussed in table 1 can be clearly excluded with adequate radiation protection management [31].

There are two predominant purposes of occupational radiation protection [22,23]. The first is to prevent the occurrence of clinically significant radiation-induced tissue reactions by observing to dose limits that are below apparent threshold levels. The second is to limit the risk of stochastic effects, including cancer, to a reasonable level in relation to societal needs, values, benefits gained, and economic factors. The ICRP and NCRP further espouse three principles of radiation protection (justification, optimization of protection, and dose limits) as essential elements of a framework for meeting these objectives [22,23]. 
Table 1 Possible health effects

\begin{tabular}{|c|l|c|}
\hline Dose range (millisieverts) & \multicolumn{1}{|c|}{ Possible health effects } & Description \\
\hline Up to 10 & $\begin{array}{l}\text { None observed or expected (typical } \\
\text { background range) }\end{array}$ & Very low dose \\
\hline $10-100$ & $\begin{array}{l}\text { Plausible health effects but not } \\
\text { observed }\end{array}$ & Low dose \\
\hline $100-1000$ & Increase risk of cancer & Moderate dose \\
\hline Above 1000 & Acute effects (burns, vomiting) & High dose \\
\hline
\end{tabular}

An understanding of radiation doses and associated risks is necessary to avoid potential discrimination and unnecessary constraints on pregnant women while protecting the conceptus. The pregnant or potentially pregnant worker should be aware that careful planning, an understanding of the risks, and minimization of radiation dose by employing appropriate radiation safety measures can address many of her potential concerns and permit her, in most cases, to safely perform procedures without incurring significant risks to the conceptus [24].

Most radiation protection programs, regulations and guidance apply specific restrictions to the occupational exposure of pregnant workers [25].In general a pregnant worker can continue doing her job in the Diagnostic Radiology department as long as she stays behind structural protection barriers, since in this case it is very unlikely that the dose in the surface of the abdomen would exceed $2 \mathrm{mSv}$. However she should not work in all those situations in which there were no structural protection barriers to protect her. This recommendation applies to fluoroscopy and mobile radiographic and fluoroscopic screening equipment. Also pregnant workers shall not participate in any emergency program in the department [7].

\subsection{Pregnancy declaration}

The first responsibility for the protection of the conceptus lies with the woman herself to declare her pregnancy to her management as soon as the pregnancy is confirmed. However, health care organizations cannot protect workers if their pregnancy status is unknown, and most have no obligation until pregnancy is declared [15]. Once the pregnancy is declared it is responsibility of the employer to organize the working conditions of the worker to make it unlikely that the equivalent dose to the surface of the woman's abdomen (lower trunk) will exceed $2 \mathrm{mSv}$ during the remainder of the pregnancy. However, if your radiation doses are routinely reported to be quite low, e.g. less than 500 mrems per year, or less than 125 mrems per quarter, then it is unlikely that declaration of pregnancy will result in any formal change to your job duties, since the dose to your fetus during the 9 month gestation period is not likely to exceed these values [26].

\subsection{Monitoring occupational exposure for pregnant employee}

According to the Regulation on the protection of health against ionizing radiation, individual monitoring should be performed for pregnant exposed workers to assurance that it is unlikely that the equivalent dose to the surface of the woman's abdomen will exceed $2 \mathrm{mSv}$ during the remainder of the pregnancy [7]. Conformance to the dose limit is most commonly demonstrated through the use of a single personal dosimeter worn under any protective apron by the pregnant worker at waist level from the date the pregnancy is declared until delivery, sometimes an additional dosimeter is placed on the mother's abdomen, again under any radiation protective clothing [27].

Occupationally exposed radiation workers should be monitored monthly and provided with their monthly dose record [5]. The recommended dose limit applies to the fetal dose and it is not directly comparable to the dose measured on a personal dosimeter. A personal dosimeter worn by diagnostic radiology workers may overestimate fetal dose by about a factor of 10 or more. Workers in nuclear medicine and radiation therapy usually do not wear lead aprons and are exposed to higher photon energies. In spite of this, fetal doses are not likely to exceed 25 percent of the personal dosimeter measurement [28].

The Radiation Safety Officer (RSO), in conjunction with the employee's supervisor, will develop a plan to keep the employee below the predetermined exposure limit throughout the pregnancy. If the exposure limit is approached, other options should be considered on a case-by-case basis and may include reassignment or health-related leave [2]. 


\section{Regulatory requirements and guidance}

Most State and Federal regulations, international and professional organizations have Specific restrictions apply to the occupational exposure of pregnant women that guide health care organizations in protecting the health and safety of pregnant employees who work in areas where radiation is used.

The ICRP recommends that the standard of protection for the embryo and fetus should be broadly comparable to that provided for members of the general public (22). The ICRP and the European Commission recommend that, after a worker has declared her pregnancy, her working conditions should ensure that the equivalent dose to the unborn child is ALARA and unlikely to exceed $1 \mathrm{mSv}$ during at least the remainder of the pregnancy [22,29]. once pregnancy has been declared, the conceptus should be protected by applying a supplementary equivalent dose limit to the surface of the woman's abdomen (lower trunk) of $2 \mathrm{mSv}$ for the remainder of the pregnancy and by limiting intakes of radionuclides to about $1 / 20$ of the ALI [6]. This is further mandated in the IAEA and International Basic Safety Standards.

A pregnant worker can continue working in an X-ray department as long as there is reasonable assurance that the fetal dose can be kept below 1 mGy during the pregnancy. Both worker and the employer carry responsibility towards safety. The following recommendations are taken from ICRP 84:

When a medical radiation worker is known to be pregnant, there are three options that are often considered in medical radiation facilities:

- no change in assigned working duties.

- change to another area where the radiation exposure may be lower;

In diagnostic radiology, this may involve transferring a technician from fluoroscopy to CT scanning or some other area where there is less scattered radiation to workers. In nuclear medicine departments, a pregnant technician can be restricted from spending a lot of time in the radiopharmacy or working with radioiodine solutions. In radiotherapy with sealed sources, pregnant technicians or nurses might not participate in manual brachytherapy;

- change to a job that has essentially no radiation exposure.

Change to a position where there is no radiation exposure is sometimes requested by pregnant workers who realize that risks may be small but do not wish to accept any increased risk. The employer may also arrange for this in order to avoid difficulties in case the employee delivers a child with a spontaneous congenital abnormality (which occurs at a rate of about 3 in every 100 births) [28] .

The National Council on Radiation Protection and Measurements (NCRP) has recommended that special precautions be taken to limit exposure when an occupationally exposed woman could be pregnant. Specifically, the NCRP has recommended the maximum permissible dose to the fetus from occupational exposure of the expectant mother should not exceed $500 \mathrm{mrem}$ during the entire gestation period and/or $50 \mathrm{mrem}$ per month. This is approximately one-tenth of the maximum permissible occupational dose limit. Employees who become pregnant and must work with radioactive material or radiation sources during their pregnancy. Formal Declaration of Pregnancy is voluntary. After declaring her pregnancy, (NCRP) recommended the employee to receive:

- An evaluation of the radiation hazard from external and internal sources.

- Counseling from Health Physics regarding modifications of technique that will help minimize exposure to the fetus.

- A fetal monitoring badge, if appropriate.

Contact Health Physics to determine whether working area radiation levels could cause a fetus to receive 50 $\mathrm{mrem} / \mathrm{month}$ or more before birth based on personnel exposure monitor reports. [5]

The Nuclear Regulatory Commission (NRC) occupational radiation dose limits were established on the basis of recommendations by (ICRP) and (NCRP). (NRC) requires that if worker activities are such that an individual could receive more than $1 \mathrm{mSv}$ (annual effective dose), the occupational radiation protection program is required to have a fetal assessment program. No level of radiation exposure is free of some associated risk. Thus, They state that the aim of the dose limits and use of the ALARA (as low as reasonably achievable) principle for exposure levels should ensure that workplace risks are indistinguishable from those related to background radiation [30]. 
All Australian jurisdictions have uniform annual limits for public and occupational exposure to ionizing radiation: $1 \mathrm{mSv}$ for the public and $20 \mathrm{mSv}$ for workers who are occupationally exposed. For a pregnant ionizing radiation worker, the dose to the unborn child is restricted to the same as a member of the public - $1 \mathrm{mSv}$ [31].

In Spain, a specific consensus document on pregnancy and hospital practice was created in 2002 on the Spanish Council for nuclear safety, and the Spanish Society of Medical Physics. Based on the law where the fetus is considered a public member, the pregnant worker environment must guarantee that the fetus will not receive more than $1 \mathrm{mSv}$ throughout the pregnancy. Currently, the law states that the abdominal radiation dose should be less than $2 \mathrm{mSV}$ and if this is not the case, then a pregnant woman should not work there [7]

Saudi Food \& Drug Authority (SFDA) intend to regulate radiation limit for Pregnant workers who are working within an ionizing radiation environment, the pregnant worker shall be educated for the associated risk. They shall use personal and fetal dosimeter badges regardless of anticipated exposure levels. The dose to the embryo/fetus for pregnancy worker should not exceed about $1 \mathrm{mSv}$ during the remainder of the pregnancy [32]. SFDA state the important criteria to make sure that any person within the proximity of the radiological department is exposed to a level of radiation that meets with the international dose limit (Table 2).

Table 2 Summary of dose limits

\begin{tabular}{|c|c|c|c|}
\hline & Occupational exposure & $\begin{array}{l}\text { Occupational exposure } \\
\text { Apprentices of } 16 \text { to } 18 \text { years of } \\
\text { age, who are in training for } \\
\text { employment and students of } 16 \\
\text { to } 18 \text { years }\end{array}$ & $\begin{array}{c}\text { Public } \\
\text { exposure }\end{array}$ \\
\hline Effective dose & $\begin{array}{l}20 \mathrm{mSv} \text { per year ** averaged } \\
\text { periods over } 5 \text { years, with } \\
\text { no single year exceeding } 50 \\
\mathrm{mSv}\end{array}$ & $6 \mathrm{mSv}$ in a year & $\begin{array}{c}1 \mathrm{mSv} \text { in a } \\
\text { year }\end{array}$ \\
\hline $\begin{array}{l}\text { Equivalent dose to } \\
\text { the lens of the eye }\end{array}$ & $\begin{array}{l}20 \mathrm{mSv} \text { per year averaged } \\
\text { periods over } 5 \text { years, with } \\
\text { no single year exceeding } 50 \\
\mathrm{mS}\end{array}$ & $20 \mathrm{mSv}$ in a year & $\begin{array}{c}15 \mathrm{mSv} \text { in a } \\
\text { year }\end{array}$ \\
\hline $\begin{array}{l}\text { Equivalent dose to } \\
\text { the extremities } \\
\text { (hands and feet) or } \\
\text { the skin* }\end{array}$ & $500 \mathrm{mSv}$ in a year & $150 \mathrm{mSv}$ in a year & $\begin{array}{c}50 \mathrm{mSv} \text { in a } \\
\text { year }\end{array}$ \\
\hline
\end{tabular}

\footnotetext{
*The equivalent dose limits for the skin, apply to the average dose over $1 \mathrm{~cm} 2$ of the most highly irradiated areas of the skin
}

** The dose to the embryo/fetus for pregnancy worker should not exceed about $1 \mathrm{mSv}$ during the remainder of the pregnancy.

Occupational exposure can controlled by a limit on the annual effective dose of individual workers as recommended by NCRP and ICRP and propagated by various regulatory agencies. The pregnant worker and her conceptus are best protected in a facility that uses best practices for radiation safety. As with all radiation workers, they should know the risks and should take appropriate measures to optimize radiation protection.

As a summary, the most important aspects to take into account when an exposed worker is pregnant are the following:

- Women should be aware that conceptus doses maintained below the regulatory requirement of $5 \mathrm{mSv}$ (in the United States) or $1 \mathrm{mSv}$ (in the European Union) over the course of a pregnancy present no measurably increased risk to the conceptus. Practical application of this limit would correspond with a supplementary equivalent dose limit to the surface of the woman's abdomen of $2 \mathrm{mSv}$ (lower trunk).

- As soon as an exposed worker realizes she is pregnant, she must notify it to the radiation protection officer or the physician to control the occupational exposure.

- Make efforts to avoid substantial variation above a uniform monthly exposure rate (NCRP) recommends a monthly equivalent dose limit of 50 mrem to the embryo/fetus once the pregnancy is known.

- When a medical radiation worker is known to be pregnant there is no need of discontinuing in her job, it will be necessary to review carefully her exposure conditions to be adequate in each particular case. 
- An additional dosimeter ("baby badge") may be issued to the employee to wear in the abdominal region. An additional self-reading dosimeter can be issued upon request.

- It is especially important to reduce radiation dose during the first 2 to 3 months of pregnancy, efforts should be concentrated in the first trimester.

- Pregnant workers should never be placed in situations where they may have to make a decision to enter a high radiation area under emergency conditions.

Each institution should have a written radiation safety policy/ program for pregnant and potentially pregnant workers that addresses: declaration of pregnancy, occupational exposure, dosimeter use and readings, duties, and risk/benefit of additional shielding. Institutions have an obligation to publish or make their policies known regardless of the employee's pregnancy status at the time of the request.

\section{Conclusion}

The implementation of a declared pregnancy and fetal assessment program, careful planning, and minimization of radiation dose by engaging proper radiation safety measures as needed, can allow medical staff to perform duties and normal activities without incurring significant risks to the fetus, or significant interruptions of job activities for most medical workers. optimization of protection can be achieved through continuing education and training in radiation physics and radiation protection. Furthermore increasing operator awareness can lead to obvious decreases in occupational dose. Spread of basic knowledge about this subject in a clear and comprehensible way, for the public as well as for the medical staff, is one of the tasks to be carried by individuals working in the radiation protection field.

\section{Compliance with ethical standards}

\section{Acknowledgments}

The author would like to thank who participated in the present study.

\section{Disclosure of conflict of interest}

There are no conflicts of interest.

\section{References}

[1] Yeh Sherri S, et al. Occupational hazard exposures and depressive symptoms of pregnant workers. Journal of occupational and environmental medicine. 2018; 60(3): e134-e138.

[2] Hood, Joyce. The pregnant health care worker-An evidence-based approach to job assignment and reassignment. Aaohn Journal. 2008; 56(8): 329-333.

[3] NCRP. Ionizing radiation exposure of the population of the United States. NCRP Report No. 160. Bethesda, MD: National Council on Radiation Protection and Measurements. 2009.

[4] Siewert, Bettina, et al. Practice policy and quality initiatives: strategies for optimizing staff safety in a radiology department." Radiographics. 2013; 33(1): 245-261.

[5] NCRP. Preconception and prenatal radiation exposure: health effects and protective guidance. Recommendations of the National Council on Radiation Protection and Measurements. NCRP Report No. 174. Bethesda, MD: National Council on Radiation Protection and Measurements. 2013.

[6] ICRP. 1991. Recommendations of the International Commission on Radiological Protection. ICRP Publication 60. Ann. ICRP. 1990; 21(1-3).

[7] Casal E, et al. Management of Occupational exposure for pregnant workers in the medical field in Spain." 6th European ALARA Network Workshop. Occupational Exposure Optimisation in the Medical Field and Radiopharmaceutical Industry. Madrid. 2002.

[8] Nickoloff EL, Brateman L. Proposition: a pregnant resident physician should be excused from training rotations such as angiography and nuclear medicine because of the potential exposure of the fetus. Med Phys. 1999; 26: 2517-2519. 
[9] Shaw PM, Vouyouka A, Reed A. Time for radiation safety program guidelines for pregnant trainees and vascular surgeons. Journal of vascular surgery. 2012; 55: 862-868.

[10] Brent RL. Counseling patients exposed to ionizing radiation during pregnancy. Rev Panam Salud Publica. 2006; 20: 198-204.

[11] Brent RL. Saving lives and changing family histories: appropriate counseling of pregnant women and men and women of reproductive age, concerning the risk of diagnostic radiation exposures during and before pregnancy. Am J Obstet Gynecol. 2009; 200: 4-24.

[12] Finch SJ. Pregnancy during residency: a literature review. Academic medicine : journal of the Association of American Medical Colleges. 2003; 78: 418-428.

[13] Blake ME, Oates ME, Applegate K, Kuligowska E. American Association for Women R, Association of Program Directors in R. Proposed program guidelines for pregnant radiology residents: a project supported by the American Association for Women Radiologists and the Association of Program Directors in Radiology. Academic radiology. 2006; 13: 391-401.

[14] De Santis M, Di Gianantonio E, Straface G, et al. Ionizing radiations in pregnancy and teratogenesis. A review of literature. Reproductive Toxicology. 2005; 20: 323-329.

[15] ICRP. Pregnancy and medical radiation. International Commission on Radiological Protection. ICRP Publication 84. Ann of the ICRP. 2000; 30: 1-43.

[16] Cousins C. Medical radiation and pregnancy. Health Phys. 2008; 95: 551-553.

[17] McCollough CH, Schueler BA, Atwell TD, et al. Radiation exposure and pregnancy: when should we be concerned? Radiographics. 2007; 27: 909-917.

[18] ACR. ACR practice guideline for imaging pregnant or potentially pregnant adolescents and women with ionizing radiation. In: Practice Guidelines and Technical Standards. Reston, VA: American College of Radiology. 2008.

[19] Wieseler KM, Bhargava P, Kanal KM, Vaidya S, Stewart BK, Dighe MK. Imaging in pregnant patients: examination appropriateness. Radiographics. 2010; 30: 1215-1229.

[20] ICRP. Biological effects after prenatal irradiation (embryo and fetus). ICRP Publication 90. Annals of the ICRP. 2003; 33: 1-206.

[21] Radiation and Pregnancy: Information for Clinicians, National Center for Environmental Health Agency for Toxic Substances and Disease Registry CS303779-A April 29. 2019.

[22] ICRP. The Recommendations of the International Commission on Radiological Protection. ICRP publication 103. Ann ICRP. 2007; 37: 1-332.

[23] NCRP. Limitation of exposure to ionizing radiation. NCRP Report No. 116. Bethesda, MD: National Council on Radiation Protection and Measurements. 1993.

[24] Dauer, Lawrence T., et al. "Occupational radiation protection of pregnant or potentially pregnant workers in IR: a joint guideline of the Society of Interventional Radiology and the Cardiovascular and Interventional Radiological Society of Europe." Journal of Vascular and Interventional Radiology. 2015; 26(2): 171-181.

[25] Chu Bae, et al. "Radiological protection for pregnant women at a large academic medical Cancer Center." Physica Medica. 2017; 43: 186-189.

[26] Best, Patricia JM, et al. SCAI consensus document on occupational radiation exposure to the pregnant cardiologist and technical personnel. Heart, Lung and Circulation. 2011; 20(2): 83-90.

[27] Miller DL, Vano E, Bartal G, et al. Occupational radiation protection in interventional radiology: a joint guideline of the Cardiovascular and Interventional Radiology Society of Europe and the Society of Interventional Radiology. Journal of vascular and interventional radiology: JVIR. 2010; 21: 607-615.

[28] European Commission. Council Directive 2013/59/Euratom of 5 December 2013 laying down basic safety standards for protection against the dangers arising from exposure to ionising radiation, and repealing Directives 89/618/Euratom, 90/641/Euratom, 96/29/Euratom, 97/43/Euratom and 2003/122/Euratom. Off J Eur Commun. 2013; L13: 1-73.

[29] Day, Lloyd C. "NUCLEAR REGULATORY COMMISSION 10 CFR Parts 19, 20, and 50."

[30] Protection, Australian Radiation. "Australian Radiation Protection and Nuclear Safety Regulations 1999." 
World Journal of Advanced Research and Reviews, 2021, 12(03), 075-082

[31] Saudi Food \& Drug Authority. SFDA Requirements on Radiation Protection and Safety for Healthcare Providers Version Number: 2.0 , (SFDA) (2019). 